\title{
Reading Museum Exhibits: Visitors' Reading of Exhibits in Cultural Heritage Institutions and Museums
}

Valerie Brett Shaindlin, University of Hawai'i at Mānoa, USA

\begin{abstract}
The article draws upon theoretical concepts from museology and cultural, Indigenous, and feminist theories to explore intersections between diversity and reading in Cultural Heritage Institutions and Museums (CHIM). These sites are important identity-generating institutions that both preserve and perpetuate ideology and culture. Visitors read and "read into" exhibits-which are often primarily visual; it is therefore crucial for CHIMs to practice self-awareness in how they do, or do not, make information legible. Modern museums were reformist, generalized, authoritative, monologic, and definitive arbiters of culture; in these spaces, visitors necessarily read information in a cognitively passive manner. Postmodern museums, at their best, are pedagogical, decentralized, constructive, dialogic, and representative of diverse voices, experiences, and perspectives. Postmodern museums invite visitors to engage with, and sometimes even collaborate with, or contribute to, exhibits. In both instances, visitors are asked to "read" the exhibits, but in the former, reading is a unidirectional, and therefore final, transmission; in the latter, reading is a discursive, transformative process, with potential to empower. The article proposes a non-proscriptive, Indigenous, and intersectional feminist paradigm as a more equitable information-framing model for CHIM.
\end{abstract}

Keywords: feminism; identity; institutions; museology; museum exhibits

Publication Type: conceptual article

\section{Introduction}

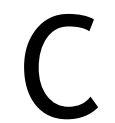

ultural Heritage Institutions and Museums (hereafter referred to as CHIM) are important identity-generating sites that both preserve and perpetuate dominant, mainstream society's ideology and culture. Visitors read and "read into" exhibits-which are often primarily visual-in these spaces. Across multiple contexts and through various methods of representation and omission, CHIM exert control over culture, both explicitly and implicitly. Contradictorily, some professionals working in CHIM choose to identify these institutions as neutral spaces whose missions are to impartially preserve and display data and artifacts. Despite these claims of neutrality, the ways in which CHIM do or do not make information legible is, in reality, inherently political. Therefore, it is crucial for the people working in and directing CHIM to incorporate self-awareness in their praxis.

CHIM are inherently political because they are inextricable from their context. In turn, context and politics invariably change over time because they exist in relation to, and are constantly interacting with, the societies from which they emerge and to which they contribute. This

The International Journal of Information, Diversity, \& Inclusion, 3(2), 2019

ISSN 2574-3430, jps.library.utoronto.ca/index.php/ijidi/index

DOI: $10.33137 /$ ijidi.v3i2.32594 
ongoing and reciprocal process preserves, generates, and disseminates information about people, and therefore affects, and is impacted by, identity production.

Visitors have not always been invited to participate in the dialogue between CHIM and society. In fact, for many decades, curators positioned museum exhibits as unilateral arbiters of culture, thinking of themselves and their work as objective, authoritative, and of superior taste (Macdonald, 2011). This attitude served to bestow control solely on those employed by the CHIM, at the necessary exclusion of museum visitors, especially visitors who may be marginalized in society.

CHIM are inherently discursive pedagogical institutions that reflect, curate, and generate normative cultural ideas. The old (modernist) museology model's structure (especially in the U.S.) is based on the white (Shim, 2015), Western, Judeo-Christian patriarchy, while the new (postmodernist) museology happily, if slowly, moves toward decolonization and an overarching vision more in line with contemporary, intersectional, and more inclusive feminist theory (Hooper-Greenhill, 2000; Message, 2006; Shim, 2015). The traditional, or old, CHIM model (hereafter referred to as the modern CHIM), is a monolithic voice that is broad, reformist, generalized, and authoritative, while the new CHIM model (hereafter referred to as the postmodern CHIM) is composed of diverse voices, specific, dialogic, decentralized, and collaborative. In this paper, drawing upon feminist and Indigenous museum scholarship, I aim to demonstrate how institutional discrimination and inequitable representation is a historical and structural challenge that, unfortunately, sometimes, can still be read in museums today. I suggest an Indigenized, collaborative, and intersectional feminist solution to the problem.

\section{The Modern Model}

The CHIM acquired its modern form during the late eighteenth and early nineteenth centuries, when governments identified culture-habits, morals, beliefs, and manners-as in dire need of transformation and regulation, especially among the subordinate classes (Bennett, 1995). Modern CHIM intended to reform society and perpetuated a centralized and exclusionary power structure. What was regarded as appropriate for pedagogic content was tightly controlled by curatorial and academic professionalism, the expectations of governing bodies, and the broader social and cultural networks of male clubs, groups, and societies (Hooper-Greenhill, 2000, p. 130).

Modern cultural institutions attempted to "regulate the performative aspects of their visitors' conduct" (Bennett, 1995, p. 6). The history of CHIM interweaves with the implications of power dynamics between three spheres: cultural institutions, government, and "the people" (Bennett, 1995, p. 109). Tensions between and among these spheres persisted throughout the formation of the modern CHIM and ultimately resulted in curators excluding many peoples from exhibits and transmitting unilateral information about "subordinate" groups of people to "subordinate" groups of people (e.g., Indigenous people, anyone non-white, women, etc.). CHIM curators, directors, and other professionals preserved their own authoritative, institutional power through exclusion, which they exerted through three primary strategies: making information legible to only a select few; overt othering; and romanticization of the past/locating the past as definitively distinct from the present (Bennet, 1995).

The International Journal of Information, Diversity, \& Inclusion, 3(2), 2019

ISSN 2574-3430, jps.library.utoronto.ca/index.php/ijidi/index

DOI: $10.33137 /$ ijidi.v3i2.32594 


\section{Legibility}

Visitors can treat exhibits like texts, in that they can subject them to a critical reading (Crang, 2003). This can be an intentional effort or a subconscious, organic process, and can be highly subjective, albeit educational. For this reason, it is imperative that CHIM professionals strive to make exhibits as legible as possible for their intended audience. In the modern period, $\mathrm{CHIM}$ professionals did the opposite: They designed institutions that were monolithic, exclusive, and disciplinary. The modern CHIM was patriarchal; it "intended to be encyclopedic, to draw together a complete collection, to act as a universal archive" (Hooper-Greenhill, 2000, p. 126).

However, through a transmission pedagogical approach, CHIM reduced what ought to be a multidimensional, complex, ambiguous, and fluid process, to a singular, unilateral, and finite trajectory or method of communicating a piece of information or message (Hooper-Greenhill, 2000). In this inequitable dynamic, the communicator-the CHIM educator, curator, and/or exhibit designer-has total control, since that person is selecting, defining, and managing the message, and therefore acts as a power broker in a very limited, linear, and one-sided transaction. The receiver (or visitor) in this situation is considered only insofar as they are judged to have correctly received the communicator's controlled and singular message; therefore, the receiver is cognitively passive (Hooper-Greenhill, 2000). In this transmission pedagogical model, knowledge was employed as a disciplinary apparatus, used to objectify experience itself, serving as a weaponization of pedagogy to deny subjectivity, and therefore diversity and agency.

The resulting relationship between communicator and receiver is an inequitable power dynamic in which certain receivers (visitors) can "see" or "read" what others cannot. A person might be fluent in a subtle and invisible language (such as theory), that is inaccessible to those who have not been educated in that specific method of interpretation. The modern CHIM therefore had a dual and contradictory nature: while intentionally designed to function as reforming or homogenizing spaces (socially elevating the lower classes through education and exposure to "culture"), modern CHIM in practice served to differentiate the elites, who quickly adopted the spaces as their own (Bennett, 1995). While simultaneously commodifying themselves and serving as instruments of the institution, elites further cemented their status by performing their education and knowledge in museum spaces, reinforcing the subtle (and invisible) language of an inequitable power dynamic in which information is-purposely or not-only legible to certain people (Bennett, 1995). While the elites were fluent in the socially constructed canons (literary, art history, etc.) and the language of the academy, that language did and often still does exclude less educated people, who have simply not been taught how to read specific methods of thought or academic disciplines. Any attempt to reform the museum to make it more politically fair must therefore include instruction so that these "invisible orders of significance it constructs" (Bennett, 1995, p. 173) can be equitably distributed amongst all the social classes and levels of education.

\section{Exclusion through Othering}

A second way that groups of people are systemically excluded from CHIM is through the process of othering. The construction of the "public" as a polite and "rational" space was predicated upon the simultaneous construction of a "negatively coded other sphere. . . from which it might be differentiated" (Bennett, 1995, p. 28). This same mechanism applies to gender construction: "origins only make sense to the extent that they are differentiated from that which they produce as derivatives" (Butler, 1991, p. 22). Sex and sexual practices are constituted by the very

The International Journal of Information, Diversity, \& Inclusion, 3(2), 2019

ISSN 2574-3430, jps.library.utoronto.ca/index.php/ijidi/index

DOI: $10.33137 /$ ijidi.v3i2.32594 
possibilities that they exclude (Butler, 1991, p. 25): The concept of man can only exist because of its perceived opposite (woman) and heterosexuality can only exist because it can be defined through its differentiation from the other (homosexuality).

The other is always necessarily positioned as deviant, and this reductive opposition produces false binaries and rigid identities. Othering also precludes multiple or diverse subjectivities, experiences, or interpretations. Both the false gender binary and the modern CHIM dichotomy (the presentation of a polite public vs. a negatively-coded other) reinforces the white heteronormative patriarchy, which defines itself by that which it is not, and therefore necessarily excludes and prohibits non-conforming identities and narratives. Nationalism similarly maintains hegemonic control by creating an "'us versus them' (self/other) construct” (E. Kosasa, 2008, p. 212). The other in modern society predictably was-and arguably remains-anyone who is not a white man (Hooper-Greenhill, 2000, p. 41). This is not only wrong and exclusionary in terms of equitable and accurate representation in CHIM, but is in fact harmful, because "relations of gender, ethnicity and class become embedded within the structures of collections; attitudes to the 'other' inform perceptions of the 'self'" (Hooper-Greenhill, 2000, p. 9). The British Museum is an example of this complicit complexity: a large and prominent national museum founded in 1753, it "remains an imperial institution in a post-imperial world" (Duthie, 2011, p. 23). They have refused dozens of requests for the repatriation of wrongfully taken items, from such countries as Greece, Egypt, and Nigeria; these continued enactments of imperialistic philosophy, principles, attitudes, and ethics reflect a group of professionals unwilling to dismantle the exclusionary othering practices of their institution (Duthie, 2011).

Othering and the lack of (or mis-) representation reinforces existing hegemony and oppressive structures with those in power at CHIM. CHIM power brokers often read representation and receive feedback that allows them to confirm and internalize their "innate" superiority, while marginalized persons who are typically not in positions of power at CHIM, simultaneously internalize their "innate" inferiority through reading inaccuracies, omissions, and/or blatant discrimination in exhibits, displays, and programs. The fact that these supposed "innate" traits are false and socially-constructed does not really matter if they are sufficiently perpetuated and reinforced through inaccurate or prejudiced portrayal (or erasure). Representation is "realized in and through its performance" (Bennett, 1995, p. 43), and because the repetition of this performance is necessary to define identity, identity "runs the risk of becoming de-instituted at every interval" (Butler, 1991, p. 24).

Group identity and culture are similarly socially constructed, and therefore require constant affirmation through repetition of (re)presentation (Duncan, 1994). Presented in CHIM, ideologies "create the reference points from which people define who they are" and "locate their place in society" (E. Kosasa, 2008, p. 212). Because repetitive performance and representation produce identity, the people behind the modern CHIM wielded the power to preserve or destroy the identities of entire cultures and peoples.

Luckily, this problem contains its own solution. The complex interplay between ideology and institutions shows up-and is legible-in representation and omission, and subsequently further reinforces itself through this very legitimization, vis-à-vis visibility or readability of cultural histories, artifacts, and exhibits. The process in which hegemony and ideology self-perpetuate is both a threat to agency and empowerment and an opportunity for both, because not only are objects and materiality unstable (Hooper-Greenhill, 2000) due to their relational context and meaning, but so is identity. Something that is inherently unstable is easier to dismantle.

The International Journal of Information, Diversity, \& Inclusion, 3(2), 2019

ISSN 2574-3430, jps.library.utoronto.ca/index.php/ijidi/index

DOI: $10.33137 /$ ijidi.v3i2.32594 


\section{The Problem with the "Past"}

Culture is "used" within society, especially in CHIM, since "collections and exhibitions embody ideas and values" (Hooper-Greenhill, 2000, p. 3). This two-way communication between ideology and cultural representation is iterative and is thusly important because modern CHIM were used to communicate "universal laws [...] presented in formal and authoritative ways to undifferentiated mass audiences" (Hooper-Greenhill, 2000, p. 2). These "universal" ideas and values were exclusionary (sexist, racist, homophobic, etc.); universality was intentionally and unintentionally weaponized to displace the specific histories of non-white peoples, which is why a specificity-oriented approach is imperative for a more just vision and intentionality for CHIM.

Institutions' desire for universality can result in an intentional romanticization of the past-and, importantly, the people who lived then-in order to create a coherent and cohesive metanarrative of a state, region, or people. Reading a place through the lens of one's own desires is a "discursive violence" (Turnbull \& Ferguson, 1997, p. 97); it is also, unfortunately, usually successful as a strategy, mainly because there is nostalgia associated with the past (Bennett, 1995). History museums in particular tend to sentimentalize the past rather than portray people in their true complexity (Bennett, 1995, p. 110); even CHIM that claim to be "of the people," or about their people, actually present people through the biased lens of the dominant culture (Bennett, 1995, p. 111). Hence, the CHIM curators, who intend to "neutrally" portray a region's history, in actuality, display their own prejudiced perspectives, which are, in turn, unique to their own contexts and temporalities.

The habit of oversimplification in CHIM is both a cause and a result of creating exhibits and spaces that are "frozen" in time (Bennett, 1995, p. 113). These frozen exhibits can be called dead: by being frozen in the past, they are lifeless and static. Clearly demarcating the past from the present is a misguided practice that disallows any potential for change, growth, or variability. This kind of time slotting creates an environment that alienates groups and individuals by closing off the possibility for interaction, contribution, or dialogue between the museum and its community or communities. This practice is particularly unfortunate when reverberations and repercussions from the past persist today (e.g., institutional racism), and CHIM fail to link those current situations to their historical origins. Such failure is equivalent to misrepresentation.

It is true that the past is that which has already occurred, so it is in a way inert or final, but $\mathrm{CHIM}$ visitors and participant/observers exist in an ever-changing, mobile, and fluid "now" or present moment, which reopens the past to new possibilities for interpretation and understanding, particularly in relation to situations concerning representation. While the past itself might not change, response to the past is ever-changing due to memory or a connective relatability, both of which can activate a dynamic interaction with the present.

The present is a constant movement, change, or reorientation toward history; in each moment we are no longer in the past moment, and we are not yet in the future moment, and this existential process is inherently and necessarily eternally ongoing. Because each moment is as such a new beginning, possibility is endless, and room opens up for multiple subjectivities, identities, and interpretations. The "truth" is inherently slippery, and our perspectives ought to, and do, constantly change; that cycle is, in fact, the learning process. If CHIM are to be pedagogical, they therefore cannot create closed-off exhibits frozen in time. The context in which we attempt to understand and analyze the past is very messy and complicated, and underscores the necessity of commensurately complex, "living" exhibits that are dynamic and

The International Journal of Information, Diversity, \& Inclusion, 3(2), 2019

ISSN 2574-3430, jps.library.utoronto.ca/index.php/ijidi/index

DOI: $10.33137 /$ ijidi.v3i2.32594 
dialogic.

The master narratives or "universal stories" of the modern CHIM were intended to validate simplification and contextualization of the 'real' world into a more manageable representation (Hooper-Greenhill, 2000, p. 24). However, this approach is counterproductive to the members of society, especially those belonging to marginalized groups. In reality, there is no one absolute truth, and if it appears to be the case, it is likely because the dominant social group has successfully monopolized the narrative.

Whether through the nation's metanarrative or exclusion from it, "material culture is vital to community identities" (Cooper, 2008, p. 84). By producing and reinforcing an oversimplified master narrative, CHIM continue to function paternalistically, serving to illustrate the nation state in a way that, even when inclusive, is also supposed to be elevated in taste (i.e., "high culture"). Such elitism continues to reproduce class division and the (oversimplified and therefore misleading) metanarrative.

Singular narratives are reinforced through persistent production or what has been identified as repetitive or continuous performativity. Production is performed through control of images, artifacts, and other audiovisual representation (and it is imperative to remember that what is not shown, or what is suppressed, is just as important as what is displayed). In CHIM, marginalized or minority beliefs and practices are vulnerable for this reason (Cooper, 2008). The solution to this problem is its inverse: create and introduce diverse and complex narratives. Stories in all formats can supportively substantiate people's lives; by reading another person's or people's story/history, such as in an exhibit, visitors can realize that their own stories are similarly worthy of being both shared and read (Minister, 1991).

\section{The Postmodern Model}

New museology moves away from the previous ideological hegemony of authoritarianism, colonialism/imperialism, and transmissional pedagogy toward nuanced, often complicated, and sometimes even conflicting narratives, ideas, and representations. CHIM professionals achieve this through a remarkably new approach: inviting collaborative input from diverse members of the community. While it might not be difficult to imagine the inclusion of the very people represented in CHIM, it is, in fact, a radical departure from past praxis. In the past, CHIM, unfortunately, normalized deep-seated power relations of advantage and disadvantage by making them visible. Luckily, in the postmodern phase, even CHIM that in the past silenced multiple points of view and dominated the same cultures they claimed to celebrate are striving to become more self-reflexive, inclusive, and collaborative. This is largely thanks to dedicated and visionary professionals. However, tensions remain between the colonizers and the colonized, even in the postcolonial era. Many of these sites retain discriminatory presentations, features, practices, and remnants from their hierarchical, patriarchal, colonial pasts. The "new" rhetoric of the postmodern CHIM is sometimes only aspirational or declarative, and not fully realized in practice (Message, 2006).

If the modern period produced a concept that was exclusionary, disciplinary, transmissive, authoritative, and presenting the "truth" as a monolithic and homogenous message, the new museum (Message, 2006), or the synonymous post-museum (Hooper-Greenhill, 2000, p. 8), emerges from the postmodern period. Key characteristics of the truly new CHIM are its small size (which means it does not attempt to be encyclopedic); an acknowledgement of its political

The International Journal of Information, Diversity, \& Inclusion, 3(2), 2019

ISSN 2574-3430, jps.library.utoronto.ca/index.php/ijidi/index

DOI: $10.33137 /$ ijidi.v3i2.32594 
context and function, or an acknowledgement that nothing is or can be neutral; self-reflexivity; fluidity and flexibility; the lack of completion, resulting in the ever-present potential for change, growth, and dialogue; multiple voices or points of view; and inclusivity (Message, 2006).

The museum ought to be a tool that can provide "comfort, inspiration, perspective and role models" (Abram, 2002, p. 128). Authoritative presentation is not the same as dialogue, and CHIM professionals ought to make their intentions explicit throughout their programming, materials, hiring practices, policies, services, displays, and exhibits. Along with community engagement, the transparency of CHIM goals and objectives would shift some agency to the visitor and offer a more respectful approach, as opposed to the previously mentioned misguided belief that the public cannot comprehend complexity. Such transparency would allow the CHIM to guide the conversation in a less authoritative way by clearly stating its goals and describing the larger context in which discussion can take place, before even presenting the narrative and/or artifacts. Institutional transparency also reduces illegibility by providing contextualizing materials and information to visitors.

A successful example of new CHIM praxis is currently available in the San Diego Museum of Man; a label on the door to the Ancient Egypt exhibit reads "This Exhibit Displays Mummified Remains." This explicitly warns those whose spiritual beliefs disallow them from entering spaces that contain human remains. Another plaque on the wall inside the exhibit partially reads, "In 2017 the Museum of Man enacted a new policy, and will no longer display human remains without receiving permission from the individual, their relatives, or ancestors." Their website elaborates:

Over the past year, we removed the remains of six people from display in this gallery. They were moved next door, to a sanctuary space, where they are being cared for along with the remains of more than 5,000 other people currently held in the Museum's collections. Many of these human remains were taken decades ago from excavated cemetery sites for the purposes of research, education, and display. This was generally done without permission from the deceased, their family, or descendant community-the standard practice at the time. . . The Museum of Man recognizes that all people should have the right to decide how their bodies, and those of their relatives and ancestors, will be treated after death. For each of the individuals whose remains are held at this museum, we will seek out descendants with whom we can consult on how to best care for the remains of their forbearers [sic]. (Museum of Man, 2018)

This policy, and the discussion about adopting it, recognizes the contributions of those earlier generations of curators and archaeologists who worked with high ideals and for the good of humanity under the ethical standards of their day. The policy reflects an evolving understanding of best practice for our institution: one that views all people as having the right to determine what happens to the remains of their ancestors. (Museum of Man, 2019)

On the other hand, one example of a new CHIM that is successfully specific and diverse, but still inadvertently perpetuates institutional erasure of Indigenous peoples, is the Japanese Cultural Center of Hawai'i (JCC). The JCC obscures Indigenous displacement and disenfranchisement visà-vis this exhibit text: "In the 50 years following World War II, significant changes resulted in all ethnic groups becoming part of the political process." This text is overly simplistic and universalizing as it fails to specify that Native Hawaiians have the right to self-determination

The International Journal of Information, Diversity, \& Inclusion, 3(2), 2019

ISSN 2574-3430, jps.library.utoronto.ca/index.php/ijidi/index

DOI: $10.33137 /$ ijidi.v3i2.32594 
under international law "because their nation was invaded and annexed by a colonial country, the United States," and that some Indigenous scholars believe that "Japanese settlers, in particular, have ascended to the ruling class and compete with the haole (whites) to control the colony of Hawai' $i$ " (Yoshinaga \& Kosasa, 2008, p. 295). However, a positive example is also found in the same exhibit. In the section about Japanese plantation workers, a quote from a "proplantation historian" is included. This provides not only a multidimensional perspective regarding labor relations, but also explicitly communicates to the visitors that this is just one of several stances. It also rejects neutrality and makes information more legible to a broader audience, by explicitly identifying the political stance of the person quoted.

Explicit text that communicates the nature of the information and the intention of the museum is useful and inclusive. However, beyond words, objects-items displayed or not displayed-are also read by the visitor. In CHIM, visitors may consciously or subconsciously absorb narratives created by the spatial relationship of one gallery and/or object to another, or those "implicit in labeling, lighting, or sound" (Mason, 2011, p. 26). CHIM are cultural stewards and influencers, able to guide the way we feel and think; in this sense, culture is constructivist (Hooper-Greenhill, 2000). Museum artifacts can be called cultural symbols because they contain their own power to shape identities and values at multiple levels. Therefore, CHIM are instrumental in the perpetuation or potential disruption of existing social values and paradigms.

\section{Indigenizing the Museum}

New CHIM ought to focus on Indigenizing in an effort to satisfy multiple, and possibly even conflicting, interests. The new CHIM intends to serve its local communities, as well as the global exchange of ideas and dialogue, by continuing to grapple publicly with difficult issues of decolonization and power as related to the past, present, and future. Indigenous resistance to American settler colonialism has been broad, and inclusive of CHIM; decolonization in CHIM has started with challenges to colonial misrepresentation (Steinman, 2016). The concept of the new CHIM has its roots in Indigenous activism. Native communities attempt to indigenize the institution of the museum by developing community or cultural centers (Cooper, 2008).

Updating or correcting erroneous or misleading exhibit information requires collaborative reflexivity and dialogue. Happily, forward-thinking CHIM "are increasingly focused on providing better responses to community concerns" (Cooper, 2008, p. 36). However, corrections and breakthroughs do not necessarily become sustainable; vigilance and protests by community members "must be periodic in order to keep moving forward" (Cooper, 2008, p. 58).

Simply paying lip service to inclusion does not mean that CHIM staff have succeeded in creating a more inclusive or collaborative space, and sometimes words and actions become muddled. For example, the National Museum of the American Indian "says it is a center of living cultures, not a museum," despite the fact that "museum" is in the name (Smith, 2009, p. 186). Similarly, simply correcting inaccuracies within existing exhibits, while important, might not be enough. Others cannot necessarily be fit into structures that are already coded as their opposite; the structures themselves might need to be changed (Beard, 2017), which is why it makes sense that Indigenous communities are already reimagining CHIM as community centers.

The concept of museum does not fit easily into traditional American Indian practices (hoarding is not a desirable trait, written labels stand in opposition to oral traditions, self-description does not fit a life of humility, intervention in the life cycle of

The International Journal of Information, Diversity, \& Inclusion, 3(2), 2019

ISSN 2574-3430, jps.library.utoronto.ca/index.php/ijidi/index

DOI: $10.33137 /$ ijidi.v3i2.32594 
material opposes the Native idea that nature's cycle is best, etc.). (Cooper, 2008, p. 137)

Even taken for granted is the Western culture's privileging of visual information and seeing in museums (K. Kosasa, 2008, p. 206). A creative solution was demonstrated by the Royal BC Museum in Victoria, when they used audio to display 34 distinct Indigenous, regional languages in their "Our Living Languages" exhibit (June 2014-June 2017), created in partnership with First Peoples' Cultural Council and advisors from Nations around the province. The Bernice Pauahi Bishop Museum in Honolulu, the largest natural and cultural history institution in Polynesia (Editors of Encyclopaedia Britannica, 2013), encourages visitors to an interactive experience via their Sleepover/Museum after Dark program: Children can tour the Hawaiian Hall and participate in hands-on activities (Bishop Museum, 2018). This program invites students to take ownership of the space by temporarily occupying it, while hands-on activities de-privilege visual-only, unilateral knowledge transmission (passive reading), instead allowing for a collaborative learning process. However, Bishop Museum (which has a somewhat fraught past, including insensitive and inappropriate handling of issues and offenses that were raised by some of its Native Hawaiian employees), is charging $\$ 25-\$ 50$ per student for this experience; the educational staff could make the program more inclusive by offering free admission for all children, or a one-price admission fee for groups, which would make the tour accessible to Native Hawaiian students.

Reimagining CHIM will necessarily require the involvement of diverse groups and individuals, and incorporation of multiple viewpoints. Producing events and exhibits as "conjoint dynamic processes" (Cooper, 2008, p. 152) enables the incorporation and representation of diverse voices and perspectives. Solutions to problems created by a white, patriarchal worldview must be solved by input from non-white, non-patriarchal stakeholders. Narratives are crucial, and people ought to be able to tell their own stories, both collectively and individually. Additionally, who has or does not have access to cultural artifacts matters. Unfortunately, "museums have been telling the controlling culture's limiting version of the Native story. . . they have been hoarding the material culture of indigenous peoples, preventing us from experiencing an intimacy with our own pasts" (Cooper, 2008, p. 2).

Generally, Native narratives have been told from outsiders' perspective. CHIM must increase involvement of Native people in the interpretation, presentation, and stewardship of their culture and history; such collaboration and sharing of agency would decrease the unfair current power dynamic, and increase the healing of communities that have been-and still are-adversely impacted by colonization (Hooper-Greenhill, 2000; Cooper, 2008; Smith, 2008; Lonetree, 2009). To combat old injustices, which have historically been covered up rather than acknowledged, museums "can enable the recasting of the present" by making visible acts, ideas, and events from the past (Hooper-Greenhill, 2000, p. 50).

The Abbe Museum of Wabanaki art, history, and culture in Maine, explicitly states on the homepage of its website that it collaborates with the Native members of its community to share their stories. Their statement also explicitly acknowledges difficult truths and reaffirms the continuity between past and present:

We are in the homeland of the Wabanaki, the People of the Dawn. We extend our respect and gratitude to the many Indigenous people and their ancestors whose rich histories and vibrant communities include the Abenaki, Maliseet, Micmac, Passamaquoddy, and Penobscot Nations and all of the Native communities who have

The International Journal of Information, Diversity, \& Inclusion, 3(2), 2019

ISSN 2574-3430, jps.library.utoronto.ca/index.php/ijidi/index

DOI: $10.33137 /$ ijidi.v3i2.32594 
lived here for thousands of generations in what is known today as Maine, New England, and the Canadian Maritimes. We make this acknowledgement aware of continual violations of water, territorial rights, and sacred sites in the Wabanaki homeland. The Abbe is honored to collaborate with the Wabanaki as they share their stories. (Abbe Museum, 2018)

The Abbe Museum's Curator of Education is a member of the Algonquin First Nation of Kitigan Zibi Anishinabeg in Quebec, and her team collaborated with schools in the Wabanaki communities to provide an educational opportunity for the Indigenous communities the museum serves. The museum provided students the opportunity to learn about the cosmos through a hands-on photography project, using telescopes owned by the Harvard-Smithsonian Center for Astrophysics. "Youth Capture the Colorful Cosmos II: Star Stories of the Dawnland," the resulting exhibit, features the children's photographs.

Amy Lonetree (2012), an enrolled citizen of the Ho-Chunk Nation of Wisconsin and an Associate Professor of History at the University of California, Santa Cruz, has identified the Ziibiwing Center of Anishinabe Culture and Lifeways as an example of a successfully Indigenized CHIM. By the Saginaw Chippewa Indian Tribe of Michigan, the exhibitions and cultural programming designed by the team at the Ziibiwing Center engage directly and explicitly with historical trauma and "unresolved grief;" this is an intentional choice and meant to encourage a healing process for Native people (Lonetree, 2012, p. 125). Some of the items in the Ziibiwing Center were repatriated from larger, colonial institutions, and the staff rooted the entire design of the space in their tribe's culture, using clear and coherent presentation of Native prophecies (oral tradition) to introduce knowledge and narrative to visitors (Lonetree, 2012). Information is legible to a more inclusive audience via audio zones (in the Anishinabe language) and text, presented in both English and the Anishinabe language (Lonetree, 2012). The space is empowering because it is legible to all, rooted in the community, created by the community, and reflexively subjective.

It is never too late for a historically exclusionary CHIM to incorporate new strategies and correct course. A label on the wall at the Peabody Museum of Archaeology and Ethnology in Boston partially reads:

Since the founding of the Peabody Museum in 1867, the museum's exhibitions have reflected changing approaches and attitudes about how to represent Native Americans. This main exhibit hall has seen many renovations through the years, the most recent of which is "Continuity and Change," which traces Native American societies from late prehistoric times to the present. ... These contemporary exhibits are the product of close collaboration between the Peabody Museum and various Native American communities. These partnerships have helped the Museum to enrich ethnographic, historical, and archaeological exhibits with new perspectives that reflect Native American voices.

This label addresses the problems with modern CHIM outlined in this paper. It acknowledges past discriminatory practices and views, and attributes them to a larger temporal context (although it could have been more explicit in labeling past views as harmful and/or problematic). It presents a continuous narrative linking the past to the present, thus demonstrating unequivocally that Native Americans are very much still alive and present today. It makes information legible by explicitly communicating to the visitors the process behind producing museum exhibits; and

The International Journal of Information, Diversity, \& Inclusion, 3(2), 2019

ISSN 2574-3430, jps.library.utoronto.ca/index.php/ijidi/index

DOI: $10.33137 /$ ijidi.v3i2.32594 
it employs collaboration between diverse and multiple voices and perspectives, particularly the historically marginalized.

Since decolonization is a process, employees who wish to contribute to a more equitable future for CHIM can always do more. One potential area that requires attention is the collection documentation strategy: "Even in collaborative, inclusive atmospheres, museum catalogs are often the last places to see change" (Turner, 2015, p. 659). An additional area of concern is that docents' training lags behind other visitor-facing educational initiatives (Murphy, 2018). Research has been done to gauge visitors' interpretations of exhibits (Horton, 2006; Peacock, 2011; Sedmak \& Brezovec, 2017), but more can be done to specifically measure whether changes to make CHIM more inclusive result in attracting additional diverse groups of visitors.

\section{An Intersectional Feminist Approach}

CHIM clearly have the potential to be places of diversity, inclusion, exchange, and possibility, but the modern model is a dead-end. Luckily, the problem contains its own solution. The very same tools of oppression that enable the discriminatory and disciplinary structure can also be employed to dismantle it. "Culture can transmit dominant values, but can also be seen as a site of resistance where dominant shared codes may be disrupted or displaced and where alternative shared codes can be produced" (Hooper-Greenhill, 2000, p. 13).

Definitions and differences are neither finite nor absolute. A feminist approach to redistributing power in CHIM would include responsiveness, mutually nurturing partnerships, and diversity (Hooper-Greenhill, 2000) rather than upholding the unattainable, exclusionary, and misleading values of objectivity, neutrality, rationality, and distance. Contextualization is crucial and means viewing things in terms of their relations with other beings, items, and factors. Contexts are often described in feminist theory as assemblages. They are moving, changing, fluid, interconnected networks, systems, or structures of being. Assemblages are crucial to theorization because subjects, struggles, and relationships cannot be removed from their contexts, and "contexts have a direct bearing on the form, content, practice and normative orientation" of society (Leckie \& Buschman, 2010, p. vii).

Similarly, CHIM exist within contexts and assemblages, and new CHIM "often seek reinvigoration via contextualization" (Message, 2006, p. 25). All knowledge is similarly contextual, as it "depends on the standpoint of the knower" (Hooper-Greenhill, 2000, p. 77). Subjectivities are always relative, which means, try as they may, CHIM can never fully control the visitor's experience or reading of exhibits. The word "reading" evokes written materials, such as books; however, any information that is processed by the brain via the senses can be said to be read. "Read" is both noun and verb; something can be passively read, but the reader is always necessarily active. Read, the verb, refers to figuring something out, considering, or discovering; it signifies an exchange taking place, one to which the reader necessarily brings something.

CHIM perpetuate the dominant societal ideology; unfortunately, throughout history, sexist ideas about gender have united men across race, ability, and especially class divisions. Successful systems of oppression, such as the patriarchy, produce individuals willing to continually strive toward beliefs and habits that benefit and sustain the system that constrains them and others (Weeks, 2011). Considering that CHIM have been products of and contributors to the continuation of the patriarchy, it is no surprise that many have helped perpetuate this oppressive and misrepresentative system. Acceptance and acknowledgement of the past is a basis for

The International Journal of Information, Diversity, \& Inclusion, 3(2), 2019

ISSN 2574-3430, jps.library.utoronto.ca/index.php/ijidi/index

DOI: $10.33137 /$ ijidi.v3i2.32594 
approaching and manifesting the future (Weeks, 2011); indeed, the acceptance of what is required is the preliminary stage of change or growth. This is why refusal to collectively acknowledge the imperialist, racist, and sexist past on the part of some professionals is holding CHIM back from reaching their full potential.

Addressing "the human needs for shared ownership, belonging, justice, and empowerment" can be a major challenge for some CHIM professionals, even those working with community representatives (Fouseki, 2010, p. 180). If CHIM professionals wish to make their institutions socially inclusive, they must keep at it, and recognize and acknowledge past injustices, while incorporating multiple perspectives, moving forward. CHIM professionals must take on issues of identity and culture (Hooper-Greenhill, 2000, p. 2). It is imperative that they take a new approach toward engagement or collaboration and multiple viewpoints, because interpretation is a dynamic process, and one that is "not singular, but multiple" (Hooper-Greenhill, 2000, p. 5) and deriving from a range of starting points.

Professionals who work in and contribute to CHIM can recognize the "diverse, fluid, and multiple nature" of their own subjectivities and community membership, but often overlook it when they "engage uncritically with other communities" (Atalay, 2012, p. 82). CHIM professionals ought to try to fuse concepts of narrative, identity, and difference via interpretive strategies to push back against the "borders of dominant cultural practices" (Hooper-Greenhill, 2000, p. 140) and negotiate these contested borders where both conflict and possibilities are rife.

One goal of CHIM, both past and present, is to give institutional shape to individual and collective values; unfortunately, American CHIM have largely ignored the feminist movement since its inception (Glaser \& Zenetou, 1994, p. 3). Feminism is a social justice movement that asserts equality and a non-binary, non-prescriptive, flexible vision of the sexes, and the belief that multiple forms of oppression exist and intersect in various ways, creating complex assemblages and causing myriad unique experiences of discrimination.

Additionally, our society, CHIM included, is better at attending to the problem of individual wrongdoers, than the systems in which they operate and from which they derive their power (Weeks, 2011). This is unfortunate since, to solve many of our social problems, an overhaul of systems, not individuals, is required. This is why a feminist future for CHIM is potentially productive and would need to be spearheaded by the people working there; "power can be used to further democratic possibilities, or it can be used to uphold exclusionary values" (HooperGreenhill, 2000, p. 162). The systemic overhaul required is not limited to exhibit design. To ameliorate relationships between CHIM and communities, there must be the dedicated hiring of Indigenous people (Turner, 2015) and members of other marginalized groups, as well as explicit institutional support (budgets, policies, etc.) for their education and continued career success.

Intersectional feminism is a potentially productive and equitable future for museums because it is intolerant of myriad social injustices, considers context, examines structures, embraces specificity and dialogue, and provides space for imagining possibilities. It encourages living culture, flexibility, diversity, and dialogue. The future of CHIM ought to be one of possibility; prescription would reproduce the singular and authoritative paradigm of the past. While Cooper, Hooper-Greenhill, Message, and the other writers cited in this paper provide fantastic ideas for the way forward, CHIM ought to be wary of one-size-fits-all approaches, as they risk reinforcing/reinstating the monolithic model of the modern era.

The International Journal of Information, Diversity, \& Inclusion, 3(2), 2019

ISSN 2574-3430, jps.library.utoronto.ca/index.php/ijidi/index

DOI: $10.33137 /$ ijidi.v3i2.32594 
Rather, by drawing on these and other scholars for inspiration, CHIM might be better able to serve their communities and society at large. One way to do so is by embracing a feminist goal and, therefore, allowing space for more possibilities, including but not limited to the concepts of the new- or post-CHIM. This feminism must be intersectional because systems of power and oppression are inextricably linked. Intersectionality removes opposition and dismantles false binaries because it deals with "both/and," rather than "either/or" (Crenshaw, 1991). It allows for complexity and creates the space for multiple and, sometimes, conflicting voices, perspectives, and experiences.

This is critical because "museums can be powerful identity-defining machines" (Duncan, 1994, p. 101) and "the interpretation of visual culture has political implications; it may be used to open or close possibilities for individuals, groups or communities" (Hooper-Greenhill, 2000, p. 8). Meanings are plural rather than singular (Hooper-Greenhill, 2000). Similarly, our communities and identities are, decidedly, not singular. So why should our CHIM be?

\section{Conclusion}

In modern CHIM, visitors often read information in a cognitively passive manner. Postmodern CHIM, at their best, are pedagogical, decentralized, constructive, dialogic, and representative of diverse voices, experiences, and perspectives. Postmodern CHIM invite visitors to engage, collaborate, or contribute to exhibits. In both instances, visitors are asked to "read" the exhibits, but in the former, reading is a unidirectional, and therefore final, transmission; in the latter, reading is a discursive, transformative process (Hooper-Greenhill, 2000). CHIM might aim for participation and/or experience-based pedagogical models, in which curators and educators design exhibits not to transmit knowledge, but to encourage co-creation through collaboration and interactive processes (Sandvik, 2013).

Neutrality is a myth and CHIM employees (trustees, directors, curators, interns, and all other staff members) must actively reject it. CHIM are neither neutral nor transparent sheltering spaces that they are often claimed to be (Duncan, 1994). Since all individuals and groups have different ways of reading the world, CHIM are inherently political and contested sites. Every lens through which the world is interpreted is, in a way, created. The senses do not read; the brain reads. Vision is synonymous with interpretation. Since perspective tints vision, context is critical; meanings "may be fixed provisionally, but are susceptible to being changed as the interpretive frameworks change" (Hooper-Greenhill, 2000, p. 9) and each individual perspective is a unique interpretive framework. The method of representation and contextual information provided (or not provided) within an exhibition creates a secondary, but no less important, interpretive framework. As such, exhibitions are inherently complex and multi-layered experiences, and the lack of context can equate to misrepresentation.

CHIM of the past, unfortunately, normalized deep-seated power relations of advantage and disadvantage by making them visible through intentional and unintentional choices on the part of museum professionals. As humans, we think through complex ideas using words and objects as tools to illustrate the ungraspable or theoretical. Similarly, CHIM illuminate the intangibles of our reality, reflecting ourselves back to us, at our best and at our worst. CHIM are unique in that the people who create, manage, and work in them both represent and produce society and culture. This powerful position means that these people and spaces are both reflective and reinforcing; they are both a product of their context and a producer of the reality in which they reside. By materially and textually curating and presenting the values and norms of society, $\mathrm{CHIM}$

The International Journal of Information, Diversity, \& Inclusion, 3(2), 2019

ISSN 2574-3430, jps.library.utoronto.ca/index.php/ijidi/index

DOI: $10.33137 /$ ijidi.v3i2.32594 
also affect the trajectory of history through their simultaneous indication and construction of truths.

As such, CHIM professionals are inherently engaged with their communities, whether or not they choose to listen. CHIM thus may provide a useful mirror for past and current inequalities, but they also contain the potential to correct injustices going forward. Whether the people behind them choose to acknowledge and accept it or not, CHIM has a great responsibility to take a social justice stance (Shim, 2015) or, otherwise, risk perpetuating the existing paradigms of oppression.

\section{References}

Abbe Museum. (2018). The Abbe Museum acknowledges Indigenous land. Retrieved from https://www.abbemuseum.org/

Abram, R. J. (2002). Harnessing the power of history. In R. Sandell (Ed.), Museums, society, inequality (pp. 125-141). London, UK: Routledge.

Atalay, S. (2012). Community-based archaeology: Research with, by, and for indigenous and local communities. Berkeley, CA: University of California Press.

Beard, M. (2017). Women and power: A manifesto. New York, NY: Liverlight.

Bennett, T. (1995). The birth of the museum: History, theory, politics. London, UK: Routledge.

Bishop Museum. (2018). Sleepovers/museum after dark. Retrieved from https://www.bishopmuseum.org/plan-a-trip/sleepover/

Butler, J. (1991). Imitation and gender insubordination. In D. Fuss (Ed.), Inside/Out: Lesbian theories, gay theories. New York, NY: Routledge.

Crang, M. (2003). On display: The poetics, politics and interpretation of exhibitions. In $M$. Ogborn, A. Blunt, P. Gruffudd, D. Pinder, \& J. May (Eds.), Cultural geography in practice (pp. 255-268). London, UK: Hodder Arnold.

Cooper, K. C. (2008). Spirited encounters: American Indians protest museum policies and practices. Lanham, MD: Altamira.

Crenshaw, K. (1991). Mapping the margins: Intersectionality, identity politics, and violence against women of color. Stanford Law Review, 43(6), 1241-1299.

Duncan, C. (1994). Art museums and the ritual of citizenship. In S. Pearce (Ed.), Interpreting objects and collections (pp. 279-286). London, UK: Routledge.

Duthie, E. (2011). The British Museum: An imperial museum in a post-imperial world. Public History Review, 18(2011), 12-25.

Editors of Encyclopaedia Britannica. (2013). Bishop Museum. In Encyclopaedia Britannica. Retrieved from https://www.britannica.com/topic/Bishop-Museum

The International Journal of Information, Diversity, \& Inclusion, 3(2), 2019

ISSN 2574-3430, jps.library.utoronto.ca/index.php/ijidi/index

DOI: $10.33137 /$ ijidi.v3i2.32594 
Fouseki, K. (2010). Community voices, curatorial choices: Community consultation for the 1807 exhibitions. Museum and Society, 8(3), 180-192.

Glaser, J. R., \& Zenetou, A. A. (Eds.). (1994). Gender perspectives: Essays on women in museums. Washington, DC: Smithsonian Institution Press.

Hooper-Greenhill, E. (2000). Museums and the interpretation of visual culture. London, UK: Routledge.

Horton, L. E. (2006). Avoiding history: Thomas Jefferson, Sally Hemings, and the uncomfortable public conversation on slavery. In J. O. Horton \& L. E. Horton (Eds.), Slavery and public history: The tough stuff of American memory (pp. 135-150). New York, NY: New Press.

Kosasa, E. (2008). Ideological images: U.S. nationalism in Japanese settler photographs. In C. Fujikane \& J. Y. Okamura (Eds.), Asian settler colonialism: From local governance to the habits of everyday life in Hawai ${ }^{i}$ (pp. 209-232). Honolulu, HI: University of Hawai'i Press.

Kosasa, K. (2008). Sites of erasure: The representation of settler culture in Hawai'i. In C. Fujikane \& J. Y. Okamura (Eds.), Asian settler colonialism: From local governance to the habits of everyday life in Hawai ${ }^{\prime} i$ (pp. 195-208). Honolulu, HI: University of Hawai'i Press.

Leckie, G., \& Buschman, J. (2010). Introduction: The necessity for theoretically informed critique in Library and Information Science (LIS). In G. J. Leckie, L. M. Given, \& J. Buschman (Eds.), Critical theory for library and information science: Exploring the social from across the disciplines, pp. vii-xxii. Santa Barbara, CA: ABC-CLIO.

Lonetree, A. (2009). Museums as sites of decolonization: Truth telling in national and tribal museums. In S. Sleeper-Smith (Ed.), Contesting knowledge: Museums and Indigenous perspectives (pp. 322-338). Lincoln, NE: University of Nebraska Press.

Lonetree, A. (2012). Decolonizing museums: Representing Native America in national and tribal museums. Chapel Hill, NC: University of North Carolina Press.

Macdonald, S. (2011). Expanding museum studies: An introduction. In S. Macdonald (Ed.), A companion to museum studies (pp. 1-12). Malden, MA: Blackwell.

Mason, R. (2011). Cultural theory and museum studies. In S. Macdonald (Ed.), A companion to museum studies (pp. 1-12). Malden, MA: Blackwell.

Message, K. (2006). New museums and the making of culture. Oxford, UK: Berg Publishers.

Minister, K. (1991). A feminist frame for the oral history interview. In S. B. Gluck \& D. Patai, (Eds.), Women's words: The feminist practice of oral history (pp. 27-42). New York, NY: Routledge.

Murphy, M.P.A. (2018). "Blending" docent learning: Using Google forms quizzes to increase efficiency in interpreter education at Fort Henry. Journal of Museum Education, 43(1), 47-54.

The International Journal of Information, Diversity, \& Inclusion, 3(2), 2019

ISSN 2574-3430, jps.library.utoronto.ca/index.php/ijidi/index

DOI: $10.33137 /$ ijidi.v3i2.32594 
Museum of Man. (2018). Ancient Egypt. Retrieved from

https: //www.museumofman.org/exhibits/ancient-egypt/

Museum of Man. (2019). Policy on the Curation of Human Remains at the San Diego Museum of Man. Retrieved from https://www. museumofman.org/collections/policy-curationhuman-remains-san-diego-museum-man/

Peacock, P. K. (2011). Interpreting a past: Presenting gender history at living history sites in Ontario (Doctoral dissertation). Retrieved from from ProQuest Dissertations and Theses Global. (NR78416)

Sandvik, K. (2013). Playful museums: Mobile audiences and exhibitions as game experiences. Paper presented at NORDMEDIA, Oslo, Norway. Retrieved from https: / / forskning.ku.dk/find-en-forsker/?pure=en/publications/id(1826424d-1f4d-4e068e6d-f3a7e15cef2d).html

Sedmak, G., \& Brezovec, A. (2017). Visitors’ preferences for museum interpretation: Identifying and targeting market segments. Academica Turistica, 10(2), 141-150.

Shim, J. Y. (2015). Museums taking steps forward: Pedagogical apparatus requiring strategic preparation for controversial art. Multicultural Education Review, 7(1-2), 99-107.

Smith, P.C. (2008). Critical reflections on the Our Peoples exhibit: A curator's perspective. In A. Lonetree, \& A. Cobb (Eds.), The national museum of the American Indian: Critical conversations (pp. 131-143). Lincoln, NE: University of Nebraska Press.

Smith, P. C. (2009). Everything you know about Indians is wrong. Minneapolis, MN: University of Minnesota Press.

Steinman, E. W. (2016). Decolonization not inclusion: Indigenous resistance to American settler colonialism. Sociology of Race and Ethnicity, 2(2), 219-236.

Turnbull, P., \& Ferguson, K. E. (1997). Military presence/missionary past: The historical construction of masculine order and feminine Hawaii. Women in Hawai ' $i$ : Sites, Identities, and Voices, 38, 96-107.

Turner, H. (2015). Decolonizing ethnographic documentation: A critical history of the early museum catalogs at the Smithsonian's National Museum of Natural History. Cataloging \& Classification Quarterly, 53(5-6), 658-676.

Weeks, K. (2011). The problem with work: Feminism, Marxism, antiwork politics, and postwork imaginaries. Durham, NC: Duke University Press.

Yoshinaga, I. \& Kosasa, E. (2008). Local Japanese Women for Justice (LJWJ) speak out against Daniel Inouye and the JACL. In C. Fujikane \& J. Y. Okamura (Eds.), Asian settler colonialism: From local governance to the habits of everyday life in Hawai 'i (pp. 294306). Honolulu, HI: University of Hawai'i Press.

The International Journal of Information, Diversity, \& Inclusion, 3(2), 2019

ISSN 2574-3430, jps.library.utoronto.ca/index.php/ijidi/index

DOI: $10.33137 /$ ijidi.v3i2.32594 
Valerie Brett Shaindlin (vshaindl@hawaii.edu) is a recently graduated librarian from the Library and Information Science Program at the University of Hawai'i-Mānoa in Honolulu, Hawai'i. Shaindlin is interested in intersectional feminism, cultural institutions, and social justice. She earned her undergraduate degree in Management and Business from Skidmore College, in Saratoga Springs, New York, with two minors: International Affairs and Early Childhood Education. Shaindlin has experience in business administration, management, and marketing/public relations, and is also a registered yoga teacher. Find her online @ValerieBrett.

The International Journal of Information, Diversity, \& Inclusion, 3(2), 2019

ISSN 2574-3430, jps.library.utoronto.ca/index.php/ijidi/index

DOI: $10.33137 /$ ijidi.v3i2.32594 